\title{
Association of Hepatic Steatosis and Metabolic Dysfunction With Incident Cardiovascular Disease: A Nationwide Cohort Study
}

\section{Seogsong Jeong ( $\square$ jeongseogsong@snu.ac.kr)}

Seoul National University

\section{Yun Hwan Oh}

Jeju National University School of Medicine

\section{Seulggie Choi}

Seoul National University

Jooyoung Chang

Seoul National University

\section{Sung Min Kim}

Seoul National University

\section{Joung Sik Son}

Seoul National University Hospital

\section{Gyeongsil Lee}

Seoul National University Hospital

\section{Won Kim}

Seoul Metropolitan Boramae Hospital: Seoul National University Seoul Metropolitan Government Boramae Medical Center

\section{Sang Min Park}

Seoul National University Hospital

\section{Research Article}

Keywords: cardiovascular health, metabolic abnormality, fatty liver, diabetes mellitus, obesity, hepatobiliary disease, coronary heart disease, stroke

Posted Date: March 16th, 2021

DOI: https://doi.org/10.21203/rs.3.rs-289063/v1

License: (c) (i) This work is licensed under a Creative Commons Attribution 4.0 International License. Read Full License 


\section{Abstract}

Background/purpose: Metabolic dysfunction (MD)-associated fatty liver disease (MAFLD) is new clearer nomenclature with positive diagnostic criteria on the basis of hepatic steatosis and MD, involving exclusion criteria for nonalcoholic fatty liver disease (NAFLD).

Methods: This retrospective cohort study included 333,389 participants who received health examination between 2009 and 2010 from the Korean National Health Insurance Service database. Hepatic steatosis was defined using the Korean National Health and Nutrition Examination Survey-derived NAFLD scoring system. Participants were followed over 5-6 years from the index date of health examination to 31 December 2015 for cardiovascular disease (CVD). The Cox proportional hazards regression was adopted to determine adjusted hazard ratio (aHR) with 95\% confidence interval (Cl) for CVD according to the presence of hepatic steatosis, MD, and MAFLD.

Results: This study included 179,437 men and 153,952 women with a median age of 57 years. Hepatic steatosis with MD (aHR, 2.00; 95\% Cl, 1.89-2.13) and without MD (aHR, 1.30; 95\% Cl, 1.10-1.54) significantly increased the risk of CVD compared to no steatosis without MD (reference). However, steatosis revealed no significant difference in the risk of CVD compared to no steatosis among participants with one metabolic dysfunction (aHR, 1.09; 95\% Cl, 0.91-1.30). In participants with steatosis, the presence of one and $\geq 2$ metabolic dysfunctions had aHR of $1.25(95 \% \mathrm{Cl}, 0.87-1.79)$ and 1.71 (95\% $\mathrm{Cl}, 1.22-2.41)$ compared to no $\mathrm{MD}$, respectively.

Conclusion: MAFLD was significantly associated with increased CVD risk and had better predictive performance for CVD risk compared to hepatic steatosis or metabolic dysfunction alone.

\section{Introduction}

Nonalcoholic fatty liver disease (NAFLD) was coined three decades ago by Ludwig and colleagues and defined as hepatic steatosis with the exclusion of other competing etiologies of chronic liver diseases. [1, 2] Despite the various preventive and therapeutic approaches, the prevalence of NAFLD continues to increase with significant impacts on clinical medicine and economic burden to the society that nearly one billion people are being affected. [3] Considering growing knowledges on the heterogeneity of the patients with NAFLD with respect to its major drivers, including sociodemographic, clinical, and biological characteristics, an international panel of experts has suggested metabolic dysfunction (MD)-associated fatty liver disease (MAFLD) as a more articulate term that leads the research community to the renewal of the nomenclature to accelerate the development of new therapeutic approaches. [4]

In response to unmet needs in this field, the diagnosis of MAFLD can now be made using positive criteria on the basis of hepatic steatosis (HS) irrespective of alcohol consumption and concomitant liver diseases, with 3 subphenotypes including i) overweight or obesity, ii) lean or normal weight, and iii) type 2 diabetes mellitus (DM). [5] Lean or normal weight MAFLD is diagnosed if at least two MDs coexist, which includes abnormalities in waist circumference (WC), blood pressure (BP), triglycerides (TG), high-density 
lipoprotein (HDL)-cholesterol, glucose levels, insulin resistance, and high-sensitivity C-reactive protein as proposed in the Adult Treatment Panel III. [6, 7] Currently, ultrasound, vibration-controlled transient elastography, computed tomography, magnetic resonance imaging and spectroscopy, and serum biomarker-based models with available data on the diagnostic and prognostic performances, such as fatty liver index (FLI), are recommended for the detection of HS. [8, 9]

Recently, we have developed the Korean National Health and Nutrition Examination Survey (KNHANES)derived NAFLD scoring system (K-NAFLD) based on patient characteristics and serum biomarkers, which represents metabolic risk and insulin resistance. [10] Given the close relationship between NAFLD, MD, and cardiovascular disease (CVD), there is an unmet need for updates on the association of MAFLD with CVD. $[11,12]$ Herein, CVD risk was assessed according to the presence of HS, MD, and MAFLD using a Korean nationwide cohort.

\section{Methods}

\section{Study population}

The Korean National Health Insurance Service (NHIS)-National Health Screening Cohort (NHIS-HEALS) provided the study population. The NHIS of the Republic of Korea provides mandatory health insurance for all Koreans with an enrollment of nearly $98 \%$ covering almost all types of healthcare services. [13] The biannual health screening examinations of the NHIS include anthropometric measurements, laboratory examinations, medical history, prescriptions, and self-reported questionnaires for claims purposes. The NHIS-HEALS cohort is composed of approximately 500,000 participants aged between 40 and 79 years, which is about $10 \%$ of the total population. [14] This study was conducted in accordance with the STROBE guidelines for cohort studies. The institutional review board of Seoul National University Hospital approved the present study (E-2002-040-1099) in accordance with relevant guidelines and terms. The requirement for informed consents was waived as the NHIS data were anonymized according to strict confidentiality guidelines.

A total of 362,285 participants received a health examination between 2009 and 2010. Among them, 18,540 participants were excluded due to previous history of CVD before starting follow-up (index date, 1st Jan 2009) to avoid potential bias from recurrent CVD. In addition, participants with missing information, including liver function test $(n=103), W C(n=133)$, body mass index (BMl; $n=66), T G(n=430)$, fasting serum glucose (FSG; $n=4)$, total cholesterol (TC; $n=41)$, HDL-cholesterol $(n=17), B P(n=30)$, physical activity $(n=2,848)$, smoking $(n=5,243)$, and alcohol consumption $(n=1,431)$, were excluded from the analysis. Finally, the study population consisted of 333,389 participants (Fig. 1).

\section{Definition of HS, NAFLD, and MAFLD}

The HS score (HSS) was defined using the K-NAFLD score=[0.913×sex (2, if female; 1 , if male) $+0.089 \times W C+0.032 \times($ systolic $B P+F S G)+T G \times 0.007+$ alanine aminotransferase $(A L T) \times 0.105-20.929]$. [10] K-NAFLD score<-3.285 and $>0.884$ ruled out and in HS, respectively, as described previously. HS was 
defined as K-NAFLD score>0.884, whereas NAFLD required additional exclusion criteria, such as no alcohol consumption and no chronic viral hepatitis $B$ and $C$ defined using the international Classification of Diseases 10th Revision (ICD-10) code of B18, as described previously. [15] The FLI was calculated by $\left(\mathrm{e}^{0.953} \times \log _{\mathrm{e}}(\mathrm{TG})+0.139 \times \mathrm{BMI}+0.718 \times \log _{\mathrm{e}}(\mathrm{Y}\right.$-glutamyl transpeptidase; $\mathrm{Y}$ -

GT)+0.053 $\times$ WC-15.745)/(1+e $\left.0.953 \times \log _{e}(T G)+0.139 \times B M I+0.718 \times \log _{e}(Y-G T)+0.053 \times W C-15.745\right) \times 100$. [16] MAFLD was diagnosed when a participant had either i) $B M I \geq 23 \mathrm{~kg} / \mathrm{m}^{2}$, ii) $F S G \geq 126 \mathrm{mg} / \mathrm{dL}$ and/or prescription of anti-diabetic drugs, or iii) $\geq 2$ other $M D$ s, on the top of underlying HS in accordance with the international expert consensus statement. [5] $W C \geq 90 \mathrm{~cm}$ for men and $\geq 80 \mathrm{~cm}$ for women, $B P \geq 130 / 85 \mathrm{mmHg}$ or specific drug treatment, $T G \geq 150 \mathrm{mg} / \mathrm{dL}$ or specific drug treatment, HDLcholesterol $<40 \mathrm{mg} / \mathrm{dL}$ for men and $<50 \mathrm{mg} / \mathrm{dL}$ for women, and prediabetes (FSG between 100 to 125 $\mathrm{mg} / \mathrm{dL}$ ) constituted the components of the MD. Lipid accumulation product (LAP), an indicator for the severity of HS, was calculated by (WC-65)×TG for men and (WC-58)×TG for women, respectively. [17] LAP was evaluated in dichotomous groups stratified by HSS and HS index (HSI; 8×ALT/aspartate aminotransferase ratio+BMI(+2, if $\mathrm{DM} ;+2$ if female) to support the association between the severity of HS and the HSS (Supplementary Table 1). [18]

\section{Key variables}

The following covariates were considered key variables for adjustments in multivariate analyses: age, sex, insurance premium (upper half and lower half), BMI ( $\left.\mathrm{kg} / \mathrm{m}^{2}\right), \mathrm{FSG}(\mathrm{mg} / \mathrm{dL}), \mathrm{TC}(\mathrm{mg} / \mathrm{dL}), \mathrm{ALT}(\mathrm{IU} / \mathrm{L})$, smoking (never, previous, and current), alcohol consumption (never, 1-4 days/week, and $\geq 5$ days/week), physical activity [moderate-to-vigorous physical activity (MVPA) $\leq 1$ time/week and $>1$ time/week], and the Charlson comorbidity index (CCI). The CCl was calculated in accordance with a previous study. [19]

\section{Incidence of CVD}

The attending physicians were required to insert the ICD-10 code for the primary disease for each patient upon hospitalization. CVD was operatively defined as 2 or more days of hospitalization due to coronary heart disease (ICD-10 code: I20-I25) or stroke (ICD-10 code: 160-169), which were adopted by the American Heart Association guidelines. [20] The validity of the operational definition using the NHIS database was described elsewhere. [21] Starting from 1st Jan 2009, all participants were followed for CVD and death, whichever occurred earlier, till 31st Dec 2015.

\section{Statistical analysis}

Continuous and categorical variables were presented with median (interquartile range; IQR) and frequency (\%), respectively. Between-group difference was evaluated using the chi-square test and independent $t$-test for categorical and continuous variables, respectively. The incidence rate of CVD was evaluated by crude rate/1,000 person-year (PY). The Multivariate Cox proportional hazards regression model was applied for evaluation of adjusted hazard ratio (aHR) with $95 \%$ confidence interval $(\mathrm{Cl})$ for CVD according to the HS. Considering potential bias due to other cause before the follow-up 
investigation, 1- and 2-year of latent periods were washed out for sensitivity analyses. Subgroup analyses were conducted based on the key variables. For incident CVD in the overall follow-up period, receiver operating characteristic contrast estimation was carried out for NAFLD, HS, and MAFLD. A $P$ value of less than 0.05 was considered statistically significant. All data collection, mining, and statistical analyses were performed using SAS Enterprise Guide 7.1 (SAS Institute, Cary, USA).

\section{Results}

\section{Subjects characteristics}

The descriptive characteristics of the study participants are shown in Table 1. There were 179,437 men (53.8\%) and 153,952 women (46.2\%) with a median age of 57 (IQR, 51-64), a total follow-up period of $1,850,704$ PY, and a total CVD event of 32,411 cases. The median BMI and WC were $23.9 \mathrm{~kg} / \mathrm{m}^{2}$ (IQR, 22.0-25.8) and $82 \mathrm{~cm}$ (IQR, 76-87), respectively. Among entire study population, 46,319 participants (13.9\%) had HS. Compared to the participants with no HS ( $n=287,070)$, the participants with HS $(n=46,319)$ revealed significantly higher proportion of men, smoking, alcohol consumption, chronic viral hepatitis, hypertension, type $2 \mathrm{DM}$, dyslipidemia, and $\mathrm{CCl} \geq 2$, indicating that the HS group had a higher cardiometabolic risk than the non-HS group (Supplementary Table 2).

\section{Associations of HS, MD, and MAFLD with CVD risk}

We first examined the association of HS with CVD using the HSS and FLI (Supplementary Table 3). HS was in direct proportion to CVD risk since both 4th quartile groups of HSS and FLI showed highly increased CVD risk compared to 1st quartile groups. The discriminative performance of the HSS in the prediction of CVD was more effective than that of the FLI in terms of the CVD incidence rates.

Subsequently, the study population was stratified into 4 groups, including very low, low, moderate, and high HSS. The median HSS of the participants with no ruled in nor ruled out for HS were -1.690 , which was set as the cut-off for stratification into low and moderate HSS groups. The incidence rate of CVD was lowest in very low HSS, followed by low, moderate, and high HSS (Table 2). Among participants with no $\mathrm{MD}$, the aHRs were $1.30(95 \% \mathrm{Cl}, 1.17-1.44), 1.24(95 \% \mathrm{Cl}, 1.01-1.52)$, and 1.27 (95\% $\mathrm{Cl}, 0.78-2.06)$ for low, moderate, and high HSS, respectively. In addition, HS was found to significantly increase CVD risk (aHR, $1.17 ; 95 \% \mathrm{Cl}, 1.08-1.27$ ) only among participants with $\geq 2 \mathrm{MDs}$, who corresponded to the MAFLD group, suggesting that significantly increased CVD risk in overall population might be highly attributed to participants with $\geq 2$ MDs. Subgroup analysis of the effect of HS on incident CVD among subjects with MD showed that a significant trend of increased CVD risk by HS severity was observed in all subgroups except for $\mathrm{CCl}=0$ (Table 3). To confirm whether the prognostic impact of MAFLD on incident CVD is consistent across various cardiovascular risk factors, subgroup analyses were carried out after stratifying the study population into MAFLD and non-MAFLD (Fig. 2). Differing from the effect of HS on incident CVD shown in Table 3, MAFLD significantly increased CVD risk only in the age $\geq 65$ years, male, past or current smoker, $\mathrm{BMl}<25 \mathrm{~kg} / \mathrm{m}^{2}$, and $\mathrm{CCl} \geq 1$ subgroups. 
When examining the combined effect of the HSS and MD on CVD risk, both the HSS and MD additively increased the risk of CVD (Fig. 3). aHR of the HSS $>0.884$ and $\geq 2$ MDs group (i.e., the MAFLD group), was 2.22 (95\% Cl, 2.07-2.38) compared to the HSS<-3.285 and no MD group (i.e., the reference group) (Supplementary Table 4). Considering the validity of the FLI in the reflection of HS, we stratified the participants according to the IQR of the FLI. In accordance with the HSS, the 4th quartile of the FLI with $\geq 2$ MDs had the highest aHR of 2.23 .

\section{Sensitivity analyses on the associations of HS and MAFLD with CVD risk}

To support the aforementioned effects of HS and MAFLD on incident CVD, 1-2 years of latent periods were washed out to exclude potentially uncontrolled factors. After 1-year wash out, HS lost its significant association with the risk of incident CVD, whereas the association of MAFLD with incident CVD risk remained significant (aHR 1.05; 95\% Cl, 1.00-1.10; Supplementary Table 5). After washing out 2 years of latent period, similar results were found for HS and MAFLD, supporting that MAFLD is an independent predictor of incident CVD. We also adopted the HSI as a proxy for HS and NAFLD and reaffirmed that MAFLD was significantly associated with increased CVD risk (aHR, 1.15; 95\% $\mathrm{Cl}, 1.11-1.19$ ) in agreement with the findings based on the HSS and FLI (Supplementary Table 6).

\section{Comparison of NAFLD and HS with and without MD in the prediction of CVD risk}

According to the different probability levels of NAFLD ranged by the HSS cutoffs, the incidence rates of CVD were 20.0, 20.5, and 25.2 in the very low, low-to-moderate, and high probability NAFLD subgroups, respectively. (Table 4) In terms of the different probability levels of HS, the incidence rates of CVD were $12.0,18.6$, and 22.1 in the very low, low-to-moderate, and high probability HS subgroups, respectively. Furthermore, stratification of the participants with $\mathrm{HS}$ into $\mathrm{MD}=0,=1$, and $\geq 2$ revealed that the no $\mathrm{MD}$ group had the lowest incidence rate (9.0) despite the presence of HS. Of the HS subgroups, the $1 \mathrm{MD}$ group also showed a relatively lower incidence rate (14.9) compared to NAFLD with low-to-moderate probability (20.5) or HS with low-to-moderate probability (18.6), suggesting that the presence of MD may be more effective in the prediction of CVD risk compared to the presence of NAFLD or HS. Moreover, MAFLD was more predictive of overall CVD incidence in the receiver operating characteristic contrast estimation compared to NAFLD without statistical significance ( $P=0.060$; Supplementary Table 7).

\section{Associations of the different MAFLD subphenotypes with CVD risk}

When stratifying MAFLD into three subphenotypes, DM-negative overweight/obese, DM-negative normal weight, and DM-positive subphenotypes showed significantly increased CVD risk in all unadjusted and adjusted models (Table 5). However, after further adjusting for the number of MD, only DM-MAFLD subtype significantly showed an increased risk of CVD despite the attenuation of statistical significance (aHR, 1.18; 95\% Cl, 1.10-1.26), but both DM-negative overweight/obese and DM-negative normal weight subphenotypes lost their statistical significance (Table 5).

\section{Discussion}


Recently, an international consensus of experts proposed MAFLD as new clearer nomenclature with positive diagnostic criteria to surmount the limitations on an operational definition of NAFLD. [5, 22] In the current study, both HS and MD were unfavorable prognosticators of incident CVD. In particular, the composite term, MAFLD conferred the most highly elevated risk of CVD in general population. The incidence rate of CVD over the follow-up period of 5-6 years was 7.3 among participants without HS and MD, which reached up to 23.0 in participants with MAFLD. These results indicate the better performance of MAFLD in the prediction of CVD risk, circumventing the complicated use of both NAFLD and metabolic abnormalities.

The major differences between NAFLD and MAFLD are i) a set of new positive criteria for the diagnosis of MAFLD, regardless of other concomitant liver diseases and alcohol consumption, and ii) the inclusion of MDs in the diagnostic criteria. A previous study demonstrated that MD does not independently increase CVD risk among US population with NAFLD. [23] However, in the current study, CVD risk varied among different MAFLD subphenotypes. Specifically, nondiabetic MAFLD subphenotypes showed no significant associations with CVD risk, whereas diabetic MAFLD subphenotype demonstrated significantly increased risk of CVD compared to the subjects without HS, suggesting that MD may be an independent predictor of incident CVD in nondiabetic participants with HS.

Despite growing evidence on the association of either NAFLD or MD with CVD, it may be difficult to evaluate the prognostic impact of hepatic and metabolic risk factors on CVD risk in a unified and precise manner. In addition, conflicting results exist regarding the prognostic impact of NAFLD on the risk of CVD, as confirmed by the meta-analysis of 16 observational studies. [24] Recently, we developed the K-NAFLD score and confirmed its significant associations with metabolic risks and insulin resistance. [10] This scoring system allows for an operational definition of NAFLD and its application in the nationwide population-based cohort. Furthermore, CVD risk in subjects with HS should be analyzed separately in different subgroups with varying degree of metabolic risk despite clear evidence on the link between NAFLD and cardiometabolic risk. With an emerging concept of MAFLD, metabolic risk and HS seem to be now evaluable precisely in a concurrent manner.

In the current study, the HSS which was also found to be associated with HS severity, is in direct proportion to the risk of CVD even after adjustments for sociodemographic characteristics (age, sex, and insurance premium), anthropometric measurements (BMI and WC), serologic characteristics (FSG, TC, and ALT), lifestyle behaviors (smoking, alcohol consumption, and physical activity), and the CCl, suggesting that the HSS may be an independent predictor of incident CVD. Even participants with a low HSS had significantly increased CVD risk compared to those with a very low HSS. In contrast, no significant increase in CVD risk was observed in participants with 1 MD compared to no MD among participants with HS, which may reinforce the international consensus on the definition of MAFLD as HS with $\geq 2$ MDs. However, it should be validated in future large-scale confirmatory studies.

From our perspective, better performance of MAFLD versus NAFLD in the prediction of CVD risk might be attributed to the inclusion of participants with alcohol consumption and chronic viral hepatitis in the 
MAFLD group. Moreover, our results indicated that participants with HS had 3.0\% and 1.0\% higher proportion of alcohol consumption $\geq 5$ days/week and chronic viral hepatitis, respectively, than those without HS. Repeated binge drinking or excessive cumulative alcohol consumption has been confirmed to have deleterious cardiovascular health consequences by increasing the incidence of CVD and related mortality. $[25,26]$ Moreover, chronic viral hepatitis, including hepatitis $B$ and $C$, was found to be associated with increased CVD risk. [27, 28] However, considering scarce evidence in literature and a previous meta-analysis on the impact of hepatitis $B$ virus infection on coronary heart disease risk, it remains unclear whether hepatitis $B$ virus infection increases CVD risk. [29]

Although our findings confirmed the deleterious effects of HS and MD on CVD risk, the current study had several inherent limitations that need to be considered when interpreting the results. First, the homeostasis model assessment for insulin resistance and high-sensitivity C-reactive protein level, which are integral components for the diagnostic criteria of MAFLD, were not available in the NHIS database. Second, the presence and severity of HS were defined using the HSS, FLI, HSI, and LAP due to the nature of a large-scale cohort in which radiological and histological data were not available. Therefore, further prospective studies are warranted to validate our results using more accurate assessment tools of HS, such as imaging or biopsy. Finally, the current study adopted the ethnicity-specific (i.e., Asian) criteria for overweight ( $\geq 23 \mathrm{~kg} / \mathrm{m}^{2}$ ), obesity ( $\geq 25 \mathrm{~kg} / \mathrm{m}^{2}$ ), and waist circumference ( $\geq 90 \mathrm{~cm}$ for men and $\geq 80 \mathrm{~cm}$ for women). Thus, further studies using Caucasian populations with different criteria for obesity are needed to confirm our findings.

With these caveats in mind, our findings indicate that HS and MD are significantly associated with increased CVD risk. The benefits of applying MAFLD rather than NAFLD in the prediction of CVD risk include positive inclusion criteria and better discriminative ability in the stratification of individuals at different CVD risks. The incidence rate of CVD for MAFLD was 23.0, which was over 3 folds of normal population without $\mathrm{HS}$ and MD, suggesting that MAFLD needs to be considered an important risk factor for CVD, as well as a new etiologic subtype of CVD.

\section{Declarations}

\section{Acknowledgement}

Seogsong Jeong and Sung Min Kim received grants from the BK21-plus education program provided by the National Research Foundation of Korea.

\section{Funding}

Not applicable.

\section{Competing interests}

The authors declare no competing interests. 


\section{Ethics approval}

The institutional review board of Seoul National University Hospital approved the present study (E-2002040-1099) in accordance with relevant guidelines and terms.

\section{Consent to participate}

The requirement for informed consents was waived as the NHIS data were anonymized according to strict confidentiality guidelines.

\section{Consent to publication}

Not applicable.

\section{Availability of data and material}

Data used in the presents study were achieved from the NHIS. Researchers can apply for the data from the NHIS (https://nhiss.nhis.or.kr) on research purposes.

\section{Code availability}

Codes used in this study can be obtained from the corresponding author under reasonable request.

\section{References}

1. Ludwig J, Viggiano TR, McGill DB, Oh BJ. Nonalcoholic steatohepatitis: Mayo Clinic experiences with a hitherto unnamed disease. Mayo Clin Proc. 1980;55(7):434-438.

2. Younossi Z, Tacke F, Arrese M, et al. Global Perspectives on Nonalcoholic Fatty Liver Disease and Nonalcoholic Steatohepatitis. Hepatology. 2019;69(6):2672-2682.

3. Younossi Z, Anstee QM, Marietti M, et al. Global burden of NAFLD and NASH: trends, predictions, risk factors and prevention. Nat Rev Gastroenterol Hepatol. 2018;15(1):11-20.

4. Eslam M, Sanyal AJ, George J; International Consensus Panel. MAFLD: A Consensus-Driven Proposed Nomenclature for Metabolic Associated Fatty Liver Disease. Gastroenterology. 2020;158(7):1999-2014.e1.

5. Eslam M, Newsome PN, Sarin SK, et al. A new definition for metabolic dysfunction-associated fatty liver disease: An international expert consensus statement. J Hepatol. 2020;73(1):202-209.

6. Stefan N, Schick F, Häring HU. Causes, Characteristics, and Consequences of Metabolically Unhealthy Normal Weight in Humans. Cell Metab. 2017;26(2):292-300.

7. Expert Panel on Detection, Evaluation, and Treatment of High Blood Cholesterol in Adults. Executive Summary of The Third Report of The National Cholesterol Education Program (NCEP) Expert Panel on Detection, Evaluation, And Treatment of High Blood Cholesterol In Adults (Adult Treatment Panel III). JAMA. 2001;285(19):2486-2497. 
8. European Association for the Study of the Liver (EASL); European Association for the Study of Diabetes (EASD); European Association for the Study of Obesity (EASO). EASL-EASD-EASO Clinical Practice Guidelines for the management of non-alcoholic fatty liver disease. $J$ Hepatol. 2016;64(6):1388-1402.

9. Chalasani N, Younossi Z, Lavine JE, et al. The diagnosis and management of nonalcoholic fatty liver disease: Practice guidance from the American Association for the Study of Liver Diseases. Hepatology. 2018;67(1):328-357.

10. Jeong S, Kim K, Chang J, et al. Development of a simple nonalcoholic fatty liver disease scoring system indicative of metabolic risks and insulin resistance. Ann Trans/ Med. 2020;8(21):1414.

11. Kovalic AJ, Satapathy SK. The Role of Nonalcoholic Fatty Liver Disease on Cardiovascular Manifestations and Outcomes. Clin Liver Dis. 2018;22(1):141-174.

12. Mottillo S, Filion KB, Genest $J$, et al. The metabolic syndrome and cardiovascular risk a systematic review and meta-analysis. J Am Coll Cardiol. 2010;56(14):1113-1132.

13. Kwon S. Thirty years of national health insurance in South Korea: lessons for achieving universal health care coverage. Health Policy Plan. 2009;24(1):63-71.

14. Seong SC, Kim YY, Park SK, et al. Cohort profile: the National Health Insurance Service-National Health Screening Cohort (NHIS-HEALS) in Korea. BMJ Open. 2017;7(9):e016640.

15. Choi J, Kim HJ, Lee J, Cho S, Ko MJ, Lim YS. Risk of Hepatocellular Carcinoma in Patients Treated With Entecavir vs Tenofovir for Chronic Hepatitis B: A Korean Nationwide Cohort Study. JAMA Oncol. 2019;5(1):30-36.

16. Bedogni G, Bellentani S, Miglioli L, et al. The Fatty Liver Index: a simple and accurate predictor of hepatic steatosis in the general population. BMC Gastroenterol. 2006;6:33.

17. Kahn HS. The "lipid accumulation product" performs better than the body mass index for recognizing cardiovascular risk: a population-based comparison. BMC Cardiovasc Disord. 2005;5:26.

18. Lee JH, Kim D, Kim HJ, et al. Hepatic steatosis index: a simple screening tool reflecting nonalcoholic fatty liver disease. Dig Liver Dis. 2010;42(7):503-508.

19. Sundararajan V, Henderson T, Perry C, Muggivan A, Quan H, Ghali WA. New ICD-10 version of the Charlson comorbidity index predicted in-hospital mortality. J Clin Epidemiol. 2004;57(12):1288-1294.

20. Writing Group Members, Mozaffarian D, Benjamin EJ, et al. Heart Disease and Stroke Statistics-2016 Update: A Report From the American Heart Association [published correction appears in Circulation. 2016 Apr 12;133(15):e599]. Circulation. 2016;133(4):e38-e360.

21. Son JS, Choi S, Kim K, et al. Association of Blood Pressure Classification in Korean Young Adults According to the 2017 American College of Cardiology/American Heart Association Guidelines With Subsequent Cardiovascular Disease Events. JAMA. 2018;320(17):1783-1792.

22. Eslam M, Sarin SK, Wong VW, et al. The Asian Pacific Association for the Study of the Liver clinical practice guidelines for the diagnosis and management of metabolic associated fatty liver disease. Hepatol Int. 2020;10.1007/s12072-020-10094-2. 
23. Kim D, Kim WR, Kim HJ, Therneau TM. Association between noninvasive fibrosis markers and mortality among adults with nonalcoholic fatty liver disease in the United States. Hepatology. 2013;57(4):1357-1365.

24. Targher G, Byrne CD, Lonardo A, Zoppini G, Barbui C. Non-alcoholic fatty liver disease and risk of incident cardiovascular disease: A meta-analysis. J Hepatol. 2016;65(3):589-600.

25. Fernández-Solà J. Cardiovascular risks and benefits of moderate and heavy alcohol consumption. Nat Rev Cardiol. 2015;12(10):576-587.

26. Goel S, Sharma A, Garg A. Effect of Alcohol Consumption on Cardiovascular Health. Curr Cardiol Rep. 2018;20(4):19.

27. Lo MK, Lee KF, Chan NN, et al. Effects of gender, Helicobacter pylori and hepatitis B virus serology status on cardiovascular and renal complications in Chinese type 2 diabetic patients with overt nephropathy. Diabetes Obes Metab. 2004;6(3):223-230.

28. Petta S, Maida M, Macaluso FS, et al. Hepatitis C Virus Infection Is Associated With Increased Cardiovascular Mortality: A Meta-Analysis of Observational Studies. Gastroenterology. 2016;150(1):145-e16.

29. Wang Y, Xiong J, Niu M, Xu W, Xu K, Zhong H. Hepatitis B virus and the risk of coronary heart disease: A comprehensive systematic review and meta-analyses of observational studies. Int J Cardiol. 2018;265:204-209.

\section{Tables}

Table 1. Baseline characteristics of the participants 


\begin{tabular}{|ll|}
\hline Characteristic & Participants (n=333,389) \\
\hline Age, years & $57(51-64)$ \\
\hline Sex, $\mathrm{n}(\%)$ & \\
\hline Male & $179,437(53.8)$ \\
\hline Female & $153,952(46.2)$ \\
\hline Insurance premium, $\mathrm{n}(\%)^{\mathrm{a}}$ & \\
\hline Upper half & $216,989(65.1)$ \\
\hline Lower half & $116,400(34.9)$ \\
\hline Body mass index, kg/m ${ }^{2}$ & $23.9(22.0-25.8)$ \\
\hline Waist circumference, cm & $82(76-87)$ \\
\hline Systolic blood pressure, mmHg & $124(115-134)$ \\
\hline Diastolic blood pressure, mmHg & $79(70-83)$ \\
\hline Fasting serum glucose, mg/dL & $96(88-106)$ \\
\hline Total cholesterol, mg/dL & $198(175-224)$ \\
\hline Triglyceride, mg/dL & $117(83-169)$ \\
\hline HDL-cholesterol, mg/dL & $52(44-62)$ \\
\hline LDL-cholesterol, mg/dL & $117(96-140)$ \\
\hline Aspartate aminotransferase, IU/L & $24(20-29)$ \\
\hline Alanine aminotransferase, IU/L & $21(16-29)$ \\
\hline Y-glutamyl transferase, IU/L & $24(16-40)$ \\
\hline Smoking, $n$ (\%) & $116,074(34.8)$ \\
\hline Never & $214,602(5.0)$ \\
\hline Past & $60,720(18.2)$ \\
\hline Current & $57,753(17.3)$ \\
\hline Alcohol consumption, $n(\%)$ & \\
\hline Never & \\
\hline 1-4 days/week & \\
\hline Physical activity, $n$ (\%) ${ }^{b}$ & \\
\hline
\end{tabular}




\begin{tabular}{|ll|}
\hline Inactive & $180,060(54.0)$ \\
\hline Active & $153,329(46.0)$ \\
\hline Chronic viral hepatitis, $n(\%)$ & $7,884(2.4)$ \\
\hline Hypertension, $n(\%)^{c}$ & $106,008(31.8)$ \\
\hline Type 2 diabetes, $n(\%)^{d}$ & $32,148(9.6)$ \\
\hline Dyslipidemia, $n(\%)^{e}$ & $49,335(14.8)$ \\
\hline Charlson comorbidity index, $n(\%)$ & \\
\hline 0 & $125,237(37.6)$ \\
\hline 1 & $108,838(32.6)$ \\
\hline$\geq 2$ & $99,314(29.8)$ \\
\hline
\end{tabular}

Data are expressed as median (interquartile range), unless indicated otherwise. PProxy for socioeconomic status based on the National Health Insurance Service. ${ }^{b}$ Active defined as moderate-to-vigorous physical activity $>1$ time/week based on the self-reported questionnaire. 'Defined as systolic blood pressure $\geq 140$ $\mathrm{mmHg}$ or diastolic blood pressure $\geq 90 \mathrm{mmHg}$ or prescription of antihypertensive drugs. ${ }^{d}$ Defined as fasting serum glucose $\geq 126 \mathrm{mg} / \mathrm{dL}$ or prescription of antidiabetic drugs. ${ }^{e}$ Defined as total cholesterol $\geq 240 \mathrm{mg} / \mathrm{dL}$ or prescription of antidyslipidemic drugs. Acronyms: HDL, high-density lipoprotein; LDL, low-density lipoprotein.

Table 2. Association of hepatic steatosis with incident cardiovascular disease according to the HSS and presence of metabolic dysfunction 


\begin{tabular}{|c|c|c|c|c|c|}
\hline & \multicolumn{4}{|c|}{ Hepatic steatosis score } & \multirow[t]{3}{*}{$P_{\text {trend }}$} \\
\hline & Very low & Low & Moderate & High & \\
\hline & $\begin{array}{l}\text { (no } \\
\text { steatosis) }\end{array}$ & & & (steatosis) & \\
\hline HSS, range & $<-3.285$ & $\begin{array}{l}-3.285 \text { to } \\
-1.690\end{array}$ & $\begin{array}{l}-1.690 \text { to } \\
0.884\end{array}$ & $>0.884$ & \\
\hline \multicolumn{6}{|l|}{ Overall population } \\
\hline$N$ & 75,806 & 105,611 & 105,653 & 46,319 & \\
\hline Event (\%) & $5,131(6.8)$ & $9,740(9.2)$ & $11,961(11.3)$ & $5,579(12.0)$ & \\
\hline$P Y$ & 428,536 & 588,447 & 580,908 & 252,813 & \\
\hline Crude rate $/ 1,000 \mathrm{PY}$ & 12.0 & 16.6 & 20.6 & 22.1 & \\
\hline $\operatorname{aHR}(95 \% \mathrm{Cl})$ & $\begin{array}{l}1.00 \\
\text { (reference) }\end{array}$ & $\begin{array}{l}1.22(1.18- \\
1.27)^{\star \star \star}\end{array}$ & $\begin{array}{l}1.42(1.36- \\
1.48)^{\star \star \star}\end{array}$ & $\begin{array}{l}1.63(1.55- \\
1.73)^{\star \star \star}\end{array}$ & $<0.001$ \\
\hline \multicolumn{6}{|l|}{$\begin{array}{l}\text { No metabolic } \\
\text { dysfunction }\end{array}$} \\
\hline$N$ & 35,854 & 14,109 & 3,143 & 767 & \\
\hline Event (\%) & $1,493(4.2)$ & $811(5.7)$ & $176(5.6)$ & $39(5.1)$ & \\
\hline$P Y$ & 205,718 & 79,909 & 17,748 & 4,355 & \\
\hline Crude rate/1,000 PY & 7.3 & 10.1 & 9.9 & 9.0 & \\
\hline $\operatorname{aHR}(95 \% \mathrm{Cl})$ & $\begin{array}{l}1.00 \\
\text { (reference) }\end{array}$ & $\begin{array}{l}1.30(1.17- \\
1.44)^{\star \star \star}\end{array}$ & $\begin{array}{l}1.24(1.01- \\
1.52)^{\star}\end{array}$ & $\begin{array}{l}1.27(0.78- \\
2.06)\end{array}$ & $<0.001$ \\
\hline \multicolumn{6}{|l|}{$\begin{array}{l}\text { Metabolic } \\
\text { dysfunction=1 }\end{array}$} \\
\hline$N$ & 29,963 & 40,648 & 17,246 & 3,637 & \\
\hline Event (\%) & $2,406(8.0)$ & $3,181(7.8)$ & $1,432(8.3)$ & 301 (8.3) & \\
\hline$P Y$ & 168,295 & 228,335 & 96,312 & 20,220 & \\
\hline Crude rate $/ 1,000 \mathrm{PY}$ & 14.3 & 13.9 & 14.9 & 14.9 & \\
\hline $\operatorname{aHR}(95 \% \mathrm{Cl})$ & $\begin{array}{l}1.00 \\
\text { (reference) }\end{array}$ & $\begin{array}{l}1.01(0.95- \\
1.08)^{(2)}\end{array}$ & $\begin{array}{l}1.10(1.01- \\
1.20)^{\star}\end{array}$ & $\begin{array}{l}1.09(0.91- \\
1.30)^{(}\end{array}$ & 0.111 \\
\hline \multicolumn{6}{|l|}{$\begin{array}{l}\text { Metabolic } \\
\text { dysfunction } \geq 2\end{array}$} \\
\hline$N$ & 9,989 & 50,854 & 85,264 & 41,915 & \\
\hline Event (\%) & $1,232(12.3)$ & 5,748 (11.3) & $10,353(12.1)$ & $5,239(12.5)$ & \\
\hline
\end{tabular}




\begin{tabular}{|c|c|c|c|c|c|}
\hline$P Y$ & 54,524 & 280,203 & 466,848 & 228,239 & \\
\hline Crude rate $/ 1,000 \mathrm{PY}$ & 22.6 & 20.5 & 22.2 & 23.0 & \\
\hline $\operatorname{aHR}(95 \% \mathrm{Cl})$ & $\begin{array}{l}1.00 \\
\text { (reference) }\end{array}$ & $\begin{array}{l}0.96(0.90- \\
1.03)\end{array}$ & $\begin{array}{l}1.05(0.98- \\
1.13)\end{array}$ & $\begin{array}{l}1.17(1.08- \\
1.27)^{\star \star \star}\end{array}$ & $<0.001$ \\
\hline
\end{tabular}

aHR calculated using the Cox proportional hazards model after adjustments for age, sex, insurance premium, body mass index, alanine aminotransferase, smoking, alcohol consumption, physical activity, and the Charlson comorbidity index. The HSS calculated using the Korean National Health and Nutrition Survey nonalcoholic fatty liver disease score. Acronyms: HSS, hepatic steatosis score; PY, person-year; aHR, adjusted hazard ratio; $\mathrm{Cl}$, confidence interval. ${ }^{*} \mathrm{P}<0.05 .{ }^{* *} P<0.01$. ${ }^{* \star} P<0.001$.

Table 3. Subgroup analysis of the effect of hepatic steatosis on incident cardiovascular disease among participants with metabolic dysfunction 
Hepatic steatosis score

$P_{\text {trend }}$

$\begin{array}{llll}\text { Very low } & \text { Low } & \text { Moderate } & \text { High } \\ <-3.285 & -3.285 \text { to } & -1.690 \text { to } & >0.884 \\ (n=39,952) & -1.690 & 0.884 & (n=45,552)\end{array}$

Age, years

$\begin{array}{llllll}<65 & \begin{array}{l}1.00 \\ \text { (reference) }\end{array} & \begin{array}{l}0.98(0.93- \\ 1.05)\end{array} & \begin{array}{l}1.07(1.00- \\ 1.15)^{\star}\end{array} & \begin{array}{l}1.10(1.01- \\ 1.21)^{\star}\end{array} & 0.002 \\ \geq 65 & \begin{array}{lllll}\text { 1.00 } \\ \text { (reference) }\end{array} & \begin{array}{l}1.02(0.96) \\ 1.09)\end{array} & \begin{array}{l}1.12(1.04- \\ 1.20)^{\star \star}\end{array} & \begin{array}{l}1.23(1.11- \\ 1.37)^{\star \star \star}\end{array} & <0.001 \\ & & & & \end{array}$

Sex

\begin{tabular}{|c|c|c|c|c|c|}
\hline Male & $\begin{array}{l}1.00 \\
\text { (reference) }\end{array}$ & $\begin{array}{l}0.99(0.93- \\
1.05)\end{array}$ & $\begin{array}{l}1.08(1.01- \\
1.15)^{\star}\end{array}$ & $\begin{array}{l}1.16(1.06- \\
1.27)^{\star \star}\end{array}$ & $<0.001$ \\
\hline emale & $\begin{array}{l}1.00 \\
\text { (reference) }\end{array}$ & $\begin{array}{l}1.02(0.96- \\
1.10)\end{array}$ & $\begin{array}{l}1.12(1.04- \\
1.20)^{\star *}\end{array}$ & $\begin{array}{l}1.15(1.03- \\
1.28)^{*}\end{array}$ & 0.002 \\
\hline
\end{tabular}

Body mass index

\begin{tabular}{|c|c|c|c|c|c|}
\hline$<25 \mathrm{~kg} / \mathrm{m}^{2}$ & $\begin{array}{l}1.00 \\
\text { (reference) }\end{array}$ & $\begin{array}{l}1.01(0.96- \\
1.06)^{(2)}\end{array}$ & $\begin{array}{l}1.11(1.04- \\
1.18)^{\star \star \star}\end{array}$ & $\begin{array}{l}1.29(1.17- \\
1.41)^{\star \star \star}\end{array}$ & $<0.001$ \\
\hline$\geq 25 \mathrm{~kg} / \mathrm{m}$ & $\begin{array}{l}1.00 \\
\text { (reference) }\end{array}$ & $\begin{array}{l}0.90(0.79- \\
1.03)\end{array}$ & $\begin{array}{l}0.98(0.86- \\
1.12)\end{array}$ & $\begin{array}{l}0.98(0.84- \\
1.13)\end{array}$ & 0.026 \\
\hline
\end{tabular}

Smoking

\begin{tabular}{|c|c|c|c|c|c|}
\hline Never & $\begin{array}{l}1.00 \\
\text { (reference) }\end{array}$ & $\begin{array}{l}1.02(0.96- \\
1.07)\end{array}$ & $\begin{array}{l}1.12(1.05- \\
1.19)^{\star \star \star}\end{array}$ & $\begin{array}{l}1.16(1.06- \\
1.27)^{\star \star \star}\end{array}$ & $<0.001$ \\
\hline Past or current & $\begin{array}{l}1.00 \\
\text { (reference) }\end{array}$ & $\begin{array}{l}1.00(0.93- \\
1.08)\end{array}$ & $\begin{array}{l}1.08(0.99- \\
1.17)\end{array}$ & $\begin{array}{l}1.18(1.05- \\
1.31)^{\star *}\end{array}$ & $<0.001$ \\
\hline
\end{tabular}

Alcohol

consumption

$\begin{array}{llllll}\text { No } & \begin{array}{l}1.00 \\ \text { (reference) }\end{array} & 1.02(0.94- & 1.13(1.04- & 1.22(1.09- & <0.001 \\ \text { Yes } & 1.00 & 1.01(0.96- & 1.10(1.04- & 1.16(1.06- & <0.001 \\ & \text { (reference) } & 1.07) & 1.17)^{\star \star} & 1.27)^{\star \star \star} & \end{array}$

Physical activity

Inactive

$\begin{array}{lllll}1.00 & 1.01(0.96- & 1.10(1.04- & 1.16(1.06- & <0.001 \\ \text { (reference) } & 1.07)^{(1.96-} & 1.18)^{\star \star} & 1.27)^{* \star \star} & \end{array}$




\begin{tabular}{|c|c|c|c|c|c|}
\hline Active & $\begin{array}{l}1.00 \\
\text { (reference) }\end{array}$ & $\begin{array}{l}1.02(0.95- \\
1.09)\end{array}$ & $\begin{array}{l}1.12(1.03- \\
1.21)^{\star *}\end{array}$ & $\begin{array}{l}1.20(1.08- \\
1.34)^{\star *}\end{array}$ & $<0.001$ \\
\hline \multicolumn{6}{|l|}{$\mathrm{CCl}$} \\
\hline 0 & $\begin{array}{l}1.00 \\
\text { (reference) }\end{array}$ & $\begin{array}{l}1.08(0.98- \\
1.19)\end{array}$ & $\begin{array}{l}1.11(0.99- \\
1.23)^{-}\end{array}$ & $\begin{array}{l}1.19(0.95- \\
1.37)^{-}\end{array}$ & 0.320 \\
\hline$\geq 1$ & $\begin{array}{l}1.00 \\
\text { (reference) }\end{array}$ & $\begin{array}{l}0.99(0.94- \\
1.04)\end{array}$ & $\begin{array}{l}1.09(1.03- \\
1.15)^{*}\end{array}$ & $\begin{array}{l}1.17(1.08- \\
1.26)^{\star \star \star}\end{array}$ & $<0.001$ \\
\hline
\end{tabular}

Adjusted hazard ratio calculated using the Cox proportional hazards model after adjustments for age, sex, insurance premium, body mass index, systolic blood pressure, fasting serum glucose, total cholesterol, alanine aminotransferase, smoking, alcohol consumption, physical activity, and the CCl. The HSS calculated using the Korean National Health and Nutrition Survey nonalcoholic fatty liver disease score. Acronyms: HSS, hepatic steatosis score; CCl, Charlson comorbidity index. ${ }^{*} P<0.05 .{ }^{* *} P<0.01$. ${ }^{* \star *} P<0.001$.

Table 4. Associations of hepatic steatosis and MAFLD with incident cardiovascular disease

\begin{tabular}{|c|c|c|c|c|c|}
\hline & $n$ & Event (\%) & $P Y$ & $\begin{array}{l}\text { Crude rate/1,000 } \\
P Y\end{array}$ & $\operatorname{aHR}(95 \% \mathrm{Cl})$ \\
\hline \multicolumn{6}{|l|}{$N A F L D$} \\
\hline Very lowa & 48,012 & 3,419 (7.1) & 171,111 & 20.0 & 1.00 (reference) \\
\hline Low-moderate ${ }^{b}$ & 124,658 & $\begin{array}{l}14,126 \\
(11.3)\end{array}$ & 687,398 & 20.5 & $\begin{array}{l}1.30(1.24- \\
1.35)^{\star \star \star}\end{array}$ \\
\hline $\mathrm{High}^{c}$ & 23,190 & $3,169(13.7)$ & 125,952 & 25.2 & $\begin{array}{l}1.55(1.44- \\
1.65)^{\star \star \star}\end{array}$ \\
\hline \multicolumn{6}{|l|}{$\begin{array}{l}\text { Hepatic } \\
\text { steatosis }\end{array}$} \\
\hline Very low ${ }^{a}$ & 75,806 & $5,131(6.8)$ & 428,536 & 12.0 & 1.00 (reference) \\
\hline Low-moderate ${ }^{b}$ & 211,264 & $\begin{array}{l}21,701 \\
(10.3)\end{array}$ & $1,169,356$ & 18.6 & $\begin{array}{l}1.30(1.25- \\
1.34)^{\star \star \star}\end{array}$ \\
\hline$H_{i g h}{ }^{c}$ & 46,319 & $5,579(12.0)$ & 252,813 & 22.1 & $\begin{array}{l}1.55(1.47- \\
1.63)^{\star \star \star}\end{array}$ \\
\hline$M D=0$ & 767 & $39(5.1)$ & 4,355 & 9.0 & 1.00 (reference) \\
\hline$M D=1$ & 3,637 & 301 (8.3) & 20,220 & 14.9 & $1.25(0.87-1.79)$ \\
\hline$M D \geq 2$ & 41,915 & $5,239(12.5)$ & 228,239 & 23.0 & $\begin{array}{l}1.71(1.22- \\
2.41)^{\star \star \star}\end{array}$ \\
\hline
\end{tabular}


aHR calculated using the Cox proportional hazards model after adjustments for age, sex, insurance premium, body mass index, alanine aminotransferase, smoking, alcohol consumption, physical activity, and the Charlson comorbidity index. NAFLD and hepatic steatosis defined using the Korean National Health and Nutrition Survey nonalcoholic fatty liver disease score. ${ }^{\mathrm{a}} \mathrm{HSS}<-3.285$. ${ }^{\mathrm{b}} \mathrm{HSS}$ between -3.285 and 0.884. ' $\mathrm{HSS}>0.884$. Acronyms: MAFLD, metabolic dysfunction-associated fatty liver disease; $P Y$, person-year; aHR, adjusted hazard ratio; $\mathrm{Cl}$, confidence interval; $\mathrm{MD}$, metabolic dysfunction; HSS, hepatic steatosis score. ${ }^{*} P<0.05 .{ }^{* *} P<0.01 .{ }^{* \star *} P<0.001$.

Table 5. Associations of the MAFLD subphenotypes with incident cardiovascular disease

\begin{tabular}{|c|c|c|c|c|c|c|}
\hline & \multicolumn{3}{|l|}{ No MAFLD } & \multicolumn{3}{|l|}{$M A F L D$} \\
\hline & \multicolumn{3}{|c|}{ Hepatic steatosis score } & \multicolumn{3}{|c|}{ Hepatic steatosis score, high $(>0.884)$} \\
\hline & Very low & Low & Moderate & \multirow{2}{*}{$\begin{array}{l}\text { DM-negative } \\
\text { overweight/obese }^{a}\end{array}$} & \multirow{2}{*}{$\begin{array}{l}\text { DM- } \\
\text { negative } \\
\text { normal } \\
\text { weight }^{b}\end{array}$} & \multirow[t]{2}{*}{$D M^{c}$} \\
\hline & $<-3.285$ & $\begin{array}{l}-3.285 \text { to } \\
-1.690\end{array}$ & $\begin{array}{l}-1.690 \text { to } \\
0.884\end{array}$ & & & \\
\hline Event (\%) & $5,131(6.8)$ & $\begin{array}{l}9,740 \\
(9.2)\end{array}$ & $\begin{array}{l}11,961 \\
(11.3)\end{array}$ & $2,592(7.3)$ & $\begin{array}{l}333 \\
(11.5)\end{array}$ & $\begin{array}{l}2,314 \\
(15.1)\end{array}$ \\
\hline$P Y$ & 428,536 & 588,447 & 580,908 & 131,445 & 14,564 & 82,229 \\
\hline $\begin{array}{l}\text { Crude } \\
\text { rate/1,000 } \\
P Y\end{array}$ & 12.0 & 16.6 & 20.6 & 19.7 & 22.9 & 28.5 \\
\hline $\begin{array}{l}H R(95 \% \\
C I)^{d}\end{array}$ & $\begin{array}{l}1.00 \\
\text { (reference) }\end{array}$ & $\begin{array}{l}1.38 \\
(1.33- \\
1.44)^{\star \star \star}\end{array}$ & $\begin{array}{l}1.72 \\
(1.66- \\
1.78)^{\star \star \star}\end{array}$ & $1.67(1.58-1.75)^{\star * \star}$ & $\begin{array}{l}1.76 \\
(1.55- \\
1.99)^{\star \star \star}\end{array}$ & $\begin{array}{l}2.44 \\
(2.32- \\
2.57)^{\star * \star}\end{array}$ \\
\hline $\begin{array}{l}\text { aHR }(95 \% \\
C I)^{e}\end{array}$ & $\begin{array}{l}1.00 \\
\text { (reference) }\end{array}$ & $\begin{array}{l}1.22 \\
(1.18- \\
1.27)^{\star \star \star}\end{array}$ & $\begin{array}{l}1.46 \\
(1.40- \\
1.52)^{\star * \star}\end{array}$ & $1.60(1.50-1.71)^{\star * \star}$ & $\begin{array}{l}1.68 \\
(1.47- \\
1.91)^{\star \star \star}\end{array}$ & $\begin{array}{l}2.11 \\
(1.99 \\
2.25)^{\star * \star}\end{array}$ \\
\hline $\begin{array}{l}\text { aHR }(95 \% \\
C I)^{f}\end{array}$ & $\begin{array}{l}1.00 \\
\text { (reference) }\end{array}$ & $\begin{array}{l}1.22 \\
(1.18- \\
1.27)^{\star * \star}\end{array}$ & $\begin{array}{l}1.42 \\
(1.36- \\
1.47)^{* \star *}\end{array}$ & $1.55(1.45-1.65)^{\star * *}$ & $\begin{array}{l}1.55 \\
(1.36- \\
1.77)^{\star * \star}\end{array}$ & $\begin{array}{l}1.78 \\
(1.67- \\
1.89)^{\star * \star}\end{array}$ \\
\hline $\begin{array}{l}\text { aHR }(95 \% \\
C I)^{g}\end{array}$ & $\begin{array}{l}1.00 \\
\text { (reference) }\end{array}$ & $\begin{array}{l}1.05 \\
(1.00 \\
1.09)^{*}\end{array}$ & $\begin{array}{l}1.07 \\
(1.02- \\
1.12)^{\star \star}\end{array}$ & $1.02(0.95-1.10)$ & $\begin{array}{l}1.03 \\
(0.90- \\
1.18)\end{array}$ & $\begin{array}{l}1.18 \\
(1.10- \\
1.26)^{\star * \star}\end{array}$ \\
\hline
\end{tabular}

HR calculated using the Cox proportional hazards model. ${ }^{a} B M I \geq 23 \mathrm{~kg} / \mathrm{m}^{2} .{ }^{b} B M l<23 \mathrm{~kg} / \mathrm{m}^{2}$. ${ }^{c}$ Defined as fasting serum glucose $\geq 126 \mathrm{mg} / \mathrm{dL}$ or prescription of antidiabetic drugs. ${ }^{d}$ Unadjusted. ${ }^{e}$ Adjusted for age, sex, insurance premium, BMI, and alanine aminotransferase. ${ }^{f}$ Adjusted for factors involved in model $B$, smoking, alcohol consumption, physical activity, and the Charlson comorbidity index. ${ }^{g}$ Adjusted for 
factors involved in model $C$ and the number of metabolic dysfunctions. MAFLD defined using the Korean National Health and Nutrition Survey nonalcoholic fatty liver disease hepatic steatosis score. Acronyms: MAFLD, metabolic dysfunction-associated fatty liver disease; $D M$, diabetes mellitus; $P Y$, person-year; $H R$, hazard ratio; aHR, adjusted hazard ratio; $\mathrm{Cl}$, confidence interval. ${ }^{*} P<0.05 .{ }^{* *} P<0.01 .{ }^{* \star} P<0.001$.

\section{Figures}

Participants who received a health examination between 2009 and 2010 $(n=362,285)$

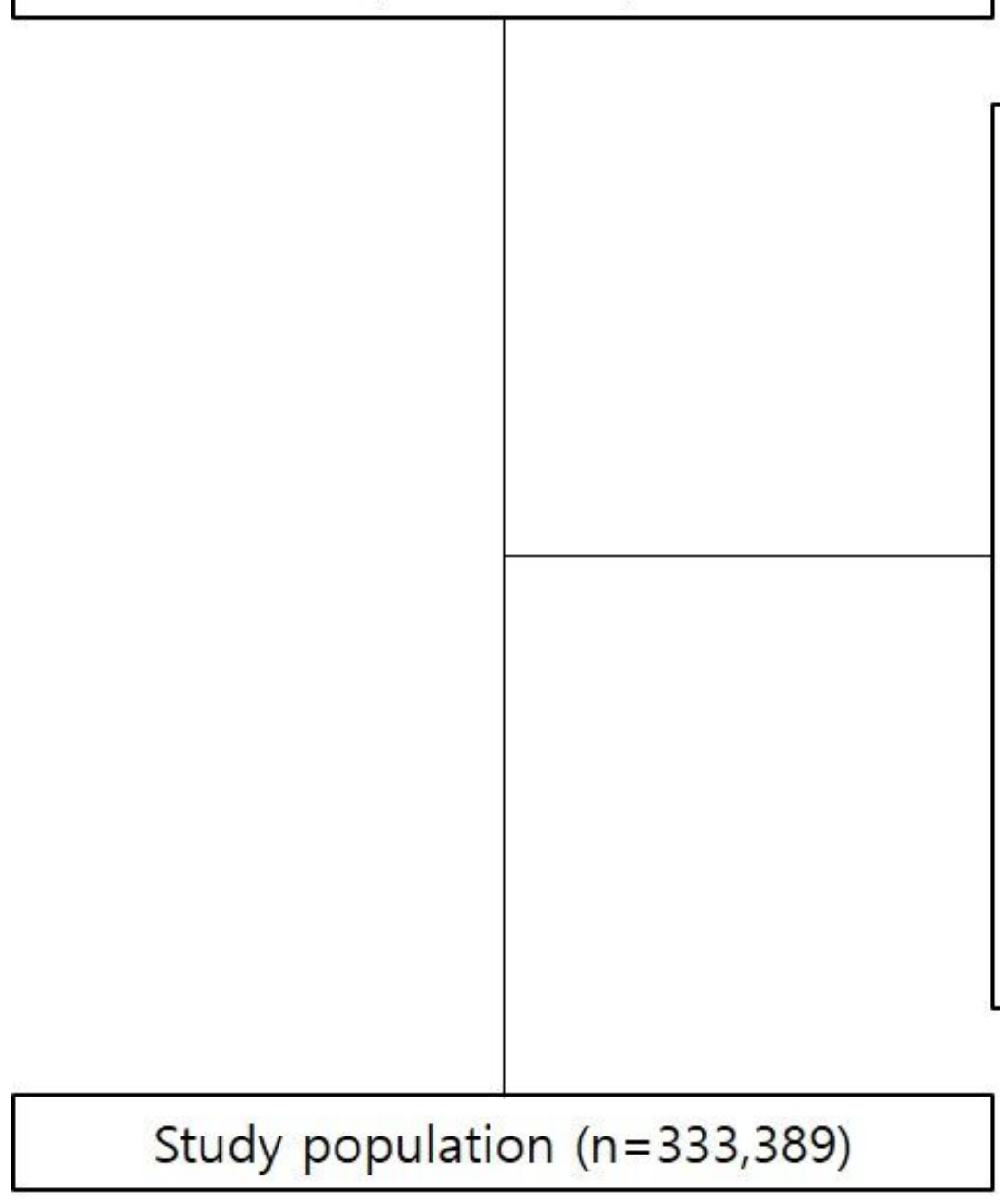

Excluded due to:

History of CVD $(n=18,540)$

Missing values

- Liver function test $(n=103)$

- Waist circumference $(n=133)$

- Body mass index $(n=66)$

- Triglyceride $(n=430)$

- Fasting serum glucose $(n=4)$

- Total cholesterol $(n=41)$

- HDL cholesterol $(n=17)$

- Blood pressure $(n=30)$

- Physical activity $(n=2,848)$

- Smoking $(n=5,253)$

- Alcohol consumption $(n=1,431)$

\section{Figure 1}

Flowchart for inclusion of study participants. 


\begin{tabular}{|c|c|c|c|c|c|c|}
\hline \multirow[b]{2}{*}{ Subgroup } & \multicolumn{3}{|c|}{ No MAFLD } & \multicolumn{3}{|c|}{ MAFLD } \\
\hline & $\mathbf{n}$ & Events & $\begin{array}{l}\text { Event/ } \\
1,000 \text { PY }\end{array}$ & n & Events & $\begin{array}{l}\text { Event/ } \\
1,000 \text { PY }\end{array}$ \\
\hline Age & & & & & & \\
\hline$<65$ years & 218,905 & 14,659 & 11.9 & 35,070 & 3,381 & 17.5 \\
\hline$\geq 65$ years & 69,291 & 12,246 & 32.7 & 10,123 & 2,125 & 39.7 \\
\hline \multicolumn{7}{|l|}{ Sex } \\
\hline Male & 149,597 & 14,758 & 17.9 & 29,840 & 3,519 & 21.7 \\
\hline Female & 138,599 & 12,147 & 15.6 & 15,353 & 1,987 & 23.6 \\
\hline \multicolumn{7}{|l|}{ Cigarette smoking } \\
\hline Never smoker & 190,230 & 17,295 & 16.2 & 24,686 & 3,102 & 22.9 \\
\hline Past/current smoker & 97,966 & 9,610 & 17.8 & 20,507 & 2,404 & 21.6 \\
\hline \multicolumn{7}{|l|}{ Body mass index } \\
\hline$<25.0 \mathrm{~kg} / \mathrm{m}^{2}$ & 203,228 & 17,874 & 15.7 & 15,769 & 2,015 & 23.4 \\
\hline$\geq 25.0 \mathrm{~kg} / \mathrm{m}^{2}$ & 84,968 & 9,031 & 19.3 & 29,424 & 3,491 & 21.8 \\
\hline \multicolumn{7}{|l|}{ Physical activity } \\
\hline Inactive & 155,110 & 15,650 & 18.1 & 24,786 & 3,228 & 23.9 \\
\hline Active & 133,086 & 11,255 & 15.2 & 20,407 & 2,278 & 20.5 \\
\hline \multicolumn{7}{|l|}{ Chronic viral hepatitis } \\
\hline Present & 6,431 & 625 & 17.6 & 1,453 & 168 & 21.2 \\
\hline Absent & 281,765 & 26,280 & 16.8 & 43,740 & 5,338 & 22.4 \\
\hline \multicolumn{7}{|c|}{ Charlson comorbidity index } \\
\hline 0 & 111,973 & 5,590 & 8.7 & 13,264 & 816 & 10.9 \\
\hline$\geq 1$ & 176,223 & 21,315 & 22.1 & 31,929 & 4,690 & 27.3 \\
\hline
\end{tabular}

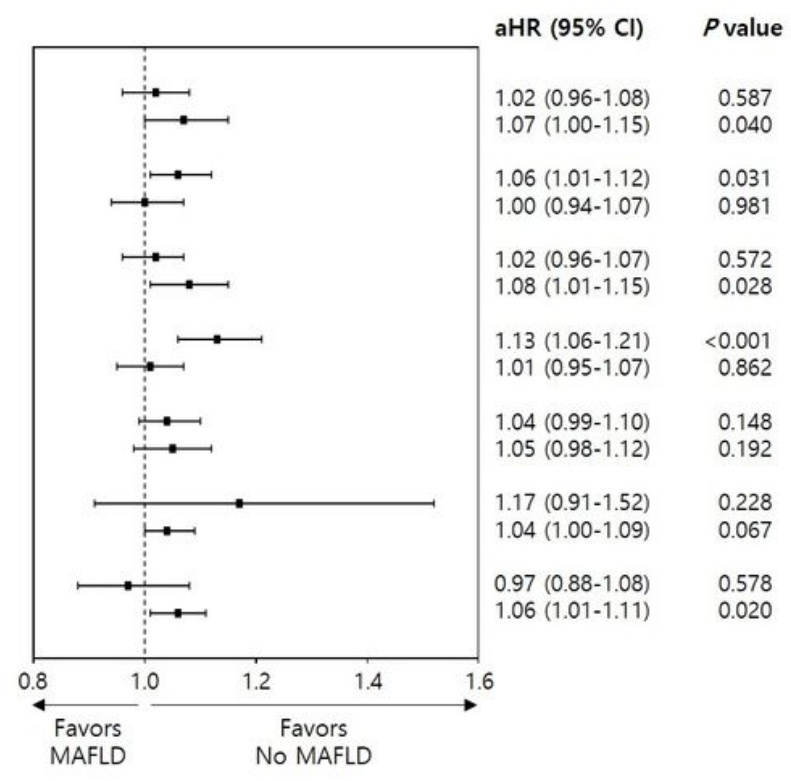

Figure 2

Subgroup analysis of the effect of MAFLD on incident cardiovascular disease. aHR calculated using the Cox proportional hazards model after adjustments for age, sex, insurance premium, body mass index, systolic blood pressure, fasting serum glucose, total cholesterol, alanine aminotransferase, smoking, alcohol consumption, physical activity, and the Charlson comorbidity index. MAFLD defined using the Korean National Health and Nutrition Survey nonalcoholic fatty liver disease score. Acronyms: MAFLD, metabolic dysfunction-associated fatty liver disease; PY, person-year; aHR, adjusted hazard ratio; $\mathrm{Cl}$, confidence interval.

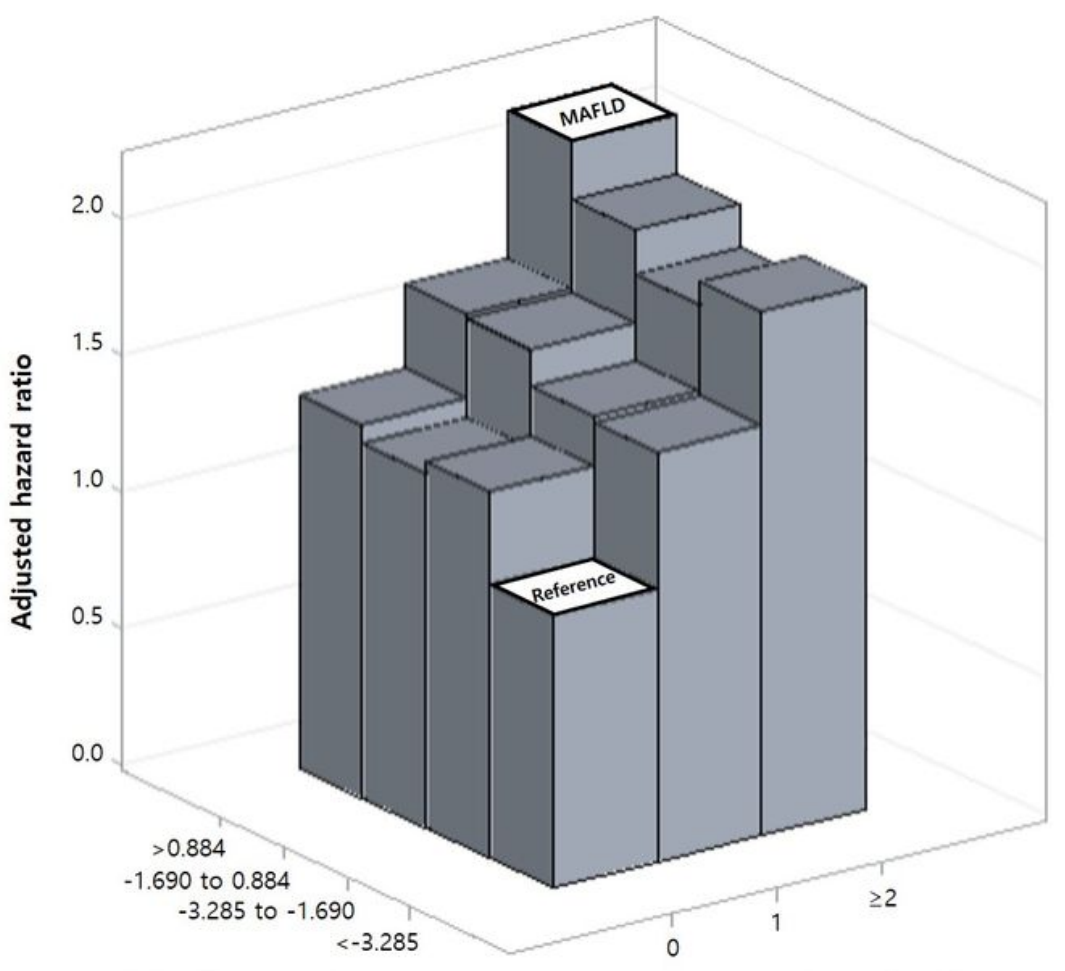

Hepatic steatosis score

Metabolic dysfunction

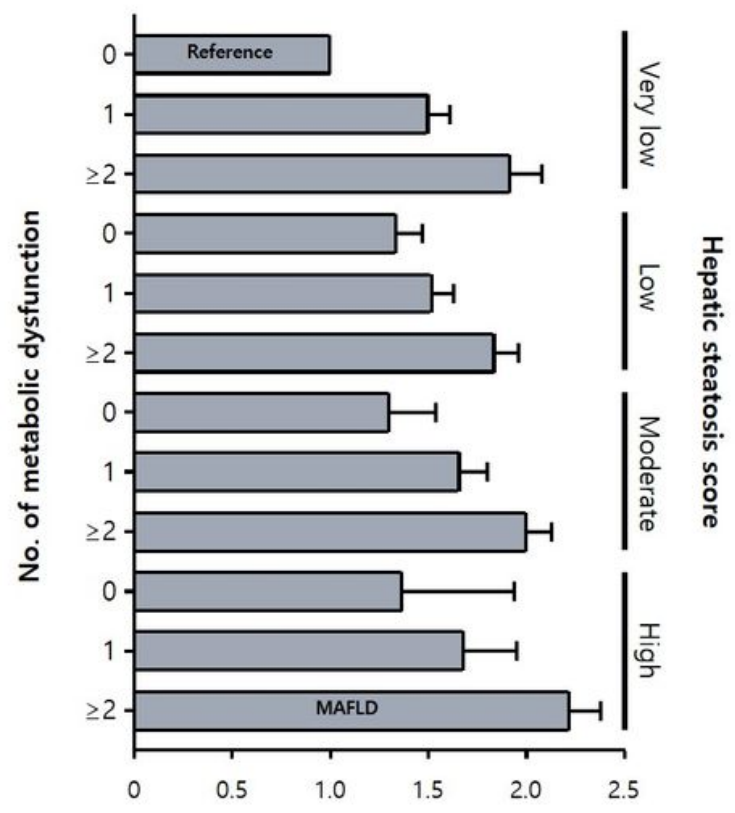

Adjusted hazard ratio $(95 \% \mathrm{Cl})$ 


\section{Figure 3}

Joint effect of hepatic steatosis and metabolic dysfunction on incident cardiovascular disease. aHR calculated using the Cox proportional hazards model after adjustments for age, sex, insurance premium, body mass index, alanine aminotransferase, smoking, alcohol consumption, physical activity, and the Charlson comorbidity index. Hepatic steatosis score calculated using the Korean National Health and Nutrition Survey nonalcoholic fatty liver disease score.

\section{Supplementary Files}

This is a list of supplementary files associated with this preprint. Click to download.

- Supplementarymaterial20210119.docx 